\title{
WATER LEVEL FLUCTUATION ASSESSMENT OF LAKE CHAD FOR ENVIRONMENTAL SUSTAINABILITY USING REMOTE SENSING AND GEOGRAPHIC INFORMATION SYSTEM TECHNIQUE
}

\author{
Alhaji Hussaini ${ }^{1.2}$, Mohd Razali Mahmud ${ }^{1}$, Kelvin Kang Wee Tang ${ }^{1}$, Auwal Garba Abubakar ${ }^{1}$ \\ ${ }^{1}$ Faculty of Built Environment and Surveying, Universiti Teknologi Malaysia, 81310 Johor Bahru, Malaysia. \\ alhajihussaini88@gmail.com \\ ${ }^{2}$ Department of Geography, Aminu Saleh College of Education Azare PMB 044, Bauchi State, Nigeria
}

KEY WORDS: Remote Sensing; GIS; Lake Chad; Landsat and Water Level.

\begin{abstract}
:
Surface water is a significant constituent of the water cycle, and is paramount for human survival, social and economic development as well as environmental sustainability. Water level shrinkage and global warming are the main phenomena that becoming worldwide environmental problems. Lake Chad has been in a critical situation in recent years due to a continuous decline in surface water and drought, over abstraction of water and climate change caused a significant change of a land cover patterns. The present study aimed to highlight the change pattern of water level in the lake over the past three decades, and the satellite images of the Lake Chad from Landsat-TM, ETM+ and OLI were analyzed to investigate the change of land cover pattern during three periods: the 1985, 2000 and 2015. Supervised classification was performed for land cover change analysis. Then the overall accuracies of the classification of Landsat-TM is 93.80, Landsat-ETM+ is 90.80 and Landsat-OLI is 86.20 respectively. The result shows that there are continuous decline of water bodies, barren land and shrub, with rapid increment of farmland and gallery forest.
\end{abstract}

\section{INTRODUCTION}

Lake Chad Basin (LCB) in Central Africa has witnessed a continuous decline in its water level over some past decades due to some factors including over abstraction and climate change, and also part of droughts. The lake which was once the 6th largest in the world has shrunk by more than $90 \%$ area for about five decades (Gao et al., 2011). The years of the major droughts fall between 1970s and 1980s and over abstraction of water mostly for irrigation purposes was a major contributor to the decreased water level in the lake and surrounding rivers, which are some of the contributors to the lake's water (Chari-logone, Komadugu-Yobe and Yedsaram/Ngadda). The shrinkage and water overuse caused significant changes to land cover which results in shoreline variation, and these could be attributed to improper water administration practices throughout the recent 50 years (Babamaaji and Lee, 2014).These issues of droughts and the lake's shrinkage have great consequences on the natural resources of the lake, as well as the standard of living of the inhabitants of the area in terms of job opportunities/poverty reduction and food security.

The Basin is described by high temperatures all over the year, little moistness except during rainy season, extreme solar radiation and solid breezes prompting a high evapotranspiration assessed to be somewhere in the range of 2,000 and 3,200 $\mathrm{mm} /$ year over the lake relying upon the area (Boronina and Ramillien, 2008; Candela et al., 2014). The yearly precipitation differs between $1,500 \mathrm{~mm}$ in the southern part of the area to under $100 \mathrm{~mm}$ in the northern part (Okonkwo and Demoz, 2014). One significant element of Lake Chad's bathymetry is a shallow ridge or 'pronounced barrier' roughly $40 \mathrm{~km}$ wide that keeps running between the northern and southern pieces of the lake.

Monitoring and assessing the lake can easily be achieved through geospatial technique, a blend of remote sensing and geographic information system (GIS). Remote sensing provides timely and accurate geospatial data and is an excellent tool for mapping, monitoring and modelling of environmental variables and processes. The widespread availability and reduced cost, remotely sensed imagery and geographic information system allow efficient mapping and detection of superficial changes of the natural resources on a greater scale. Also GIS supplies the geographic aspects of an assortment of information (Qiang and Lam, 2015). Essentially, it allows the examination of a database and provides outcomes as some sort of guide (map). Since numerous sorts of information have vital geographic aspects, a GIS can have numerous utilizations, so to see, comprehend, question, decipher and imagine information from multiple points of view and uncover to use connections, examples and patterns.

Furthermore, GIS is "an organized collection of computer hardware, software, geographic data and personnel designed to efficiently capture, store, update, analyze and display all forms of geographically referenced information" (Esri, 2012). GIS innovation has been broadly utilized as a part of various fields of study (for example; hydrology, climate change, ecology, economics, education etc.). The technological advancements brought by GIS have vital applications to numerous ecological examinations and furthermore is gainful as it can provide viable geospatial data to the policy makers in enhancing their choices for sustainable development (Chandio et al., 2013).

\section{MATERIAL AND METHODS}

\subsection{Study Area}

Lake Chad Basin, situated in west-central Africa, is geographically located between latitudes $5022^{\prime} 46.42^{\prime \prime}$ and 250 $43^{\prime} 11.11^{\prime \prime}$ north of the Equator, and longitudes $6042^{\prime} 13.89^{\prime \prime}$ and $24045^{\prime} 34.64^{\prime \prime}$ east of the Green Witch Meridian. The 
dynamic nature of the lake continually changing as a result of variation in temperatures and precipitation, which is realizable from its size, shape and depth. An assortment of natural zones bordering the lake include wetlands, wood/forest, desert, savannahs and mountains (Ovie et al., 2012). Three key drainage schemes supply its water: the Chari-Logone River (in the Central African Republic), the Komadugu-Yobe River (in Nigeria) and the Yedsaram/Ngadda River (in Cameroon).

The lake has been recognized as one of the lakes facing the most serious danger of socio-political pressure. For instance, the lake was massively greater (up to $400,000 \mathrm{~km} 2$ ) a few thousand years prior than it was in the 1960s; in those days it was known as Lake Mega Chad amid the whole twentieth century, the lake was at its peak level within 1960 and 1963. Long ago, there was a perception that the condition of the lake's bowl has exacerbated as it has shrunk by more than $90 \%$ $\left(25,000 \mathrm{~km}^{2}\right)$ from the 1960 s to date (Gao et al., 2011). The natural climate of the Lake Basin is characterized by its solid breezes, high temperatures, high evapotranspiration (evaluated at 2,200mm/annum) and fluctuating precipitation patterns. Yearly precipitation fluctuates spatially from almost $1,400 \mathrm{~mm}$ along the southern pools to under $150 \mathrm{~mm}$ close to the northern end (Okpara et al., 2015). Figure 1 shows the location of the study area.

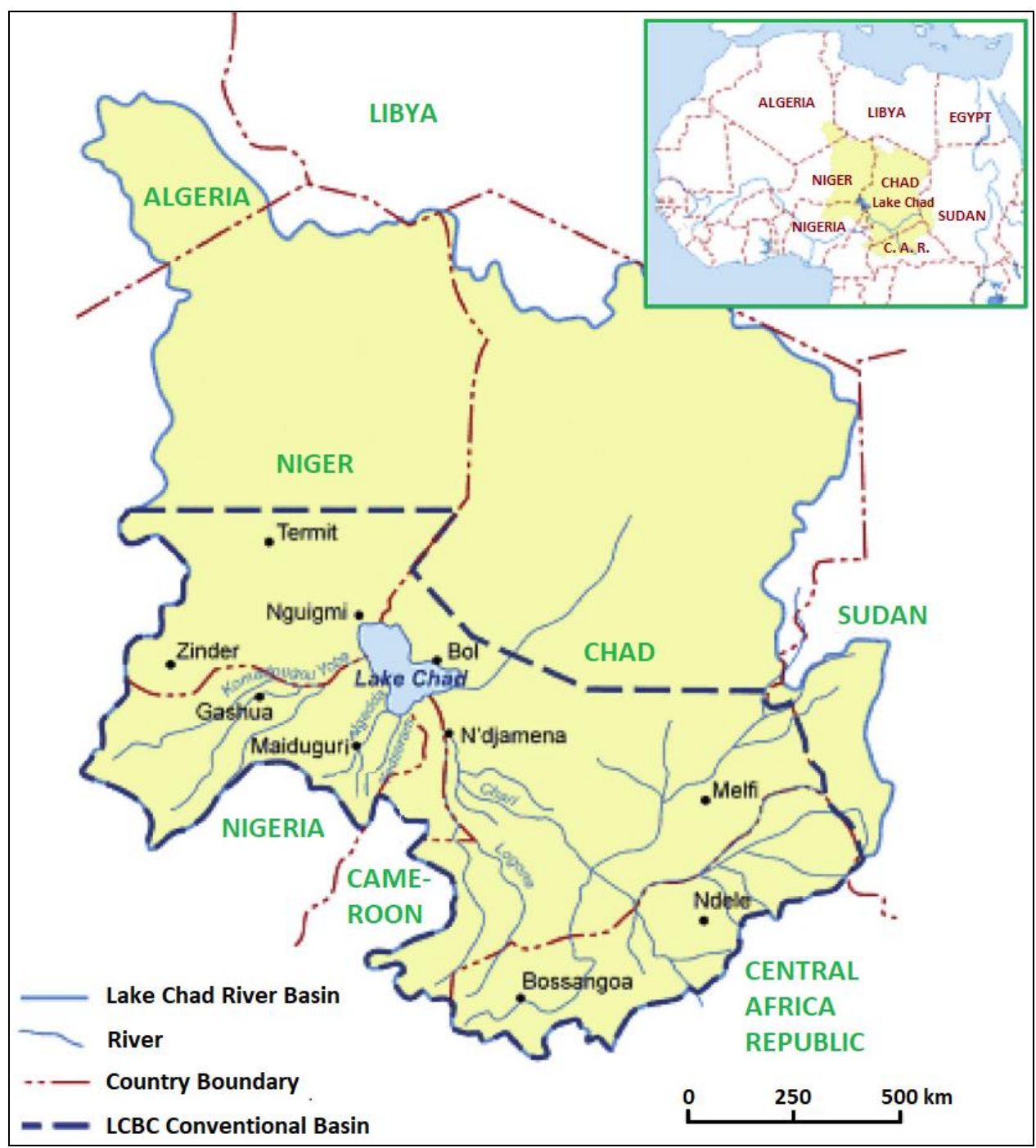

Figure 1. Study area.

\subsection{Data Collection}

Landsat imagery of three (3) epochs were utilized in this study. These include Thematic Mapper (TM) of 1985, Enhanced Thematic Mapper Plus (ETM+) of 2000 and Operational Land Imager (OLI) of 2015. The selection of the Landsat imagery could be attributed to their free access, diverse spectral bands suitable for different applications, moderate spatial resolution, and global coverage (Cenci et al., 2018; Rokni et al., 2014). All the Landsat scenes chosen as input to this investigation were imaged between December and January (winter period). The images were sourced from the Global Visualization Viewer and Earth Explore of the United State Geological Survey (USGS). Table 1 show the Landsat images used in this study in order to detect some changes. 
The International Archives of the Photogrammetry, Remote Sensing and Spatial Information Sciences, Volume XLII-4/W16, 2019 6th International Conference on Geomatics and Geospatial Technology (GGT 2019), 1-3 October 2019, Kuala Lumpur, Malaysia

Table 1. The 1985, 2000, 2015 Landsat images with their path, rows and acquisition dates

\begin{tabular}{lrrcrcc}
\hline \multirow{2}{*}{$\begin{array}{l}\text { Path/ } \\
\text { Raw }\end{array}$} & Sensor & Date & Sensor & Date & Sensor & Date \\
\cline { 2 - 7 } & Landsat TM & $20 / 10 / 1985$ & Landsat EMT+ & $19 / 11 / 2000$ & Landsat OLI & $23 / 12 / 2015$ \\
\hline $184 / 051$ & Landsat TM & $10 / 11 / 1985$ & Landsat EMT+ & $10 / 11 / 2000$ & Landsat OLI & $30 / 12 / 2015$ \\
$185 / 050$ & Landsat TM & $07 / 11 / 1985$ & Landsat EMT+ & $10 / 11 / 2000$ & Landsat OLI & $30 / 12 / 2015$ \\
$185 / 051$ & Landsat TM & $02 / 10 / 1985$ & Landsat EMT+ & $17 / 11 / 2000$ & Landsat OLI & $21 / 12 / 2015$ \\
$186 / 050$ & Landsat TM & $21 / 10 / 1985$ & Landsat EMT+ & $03 / 12 / 2000$ & Landsat OLI & $21 / 12 / 2015$ \\
\hline $186 / 051$ & & & & & \\
\hline
\end{tabular}

\subsection{Methods of Data Analysis}

The research spillited into three phases and, this section discussed the methods employed to accomplish the objective of the study. Figure 2 gives an overview of the methodology used.
At this point every single phase were carried out accordingly with a view to attain the research objective.

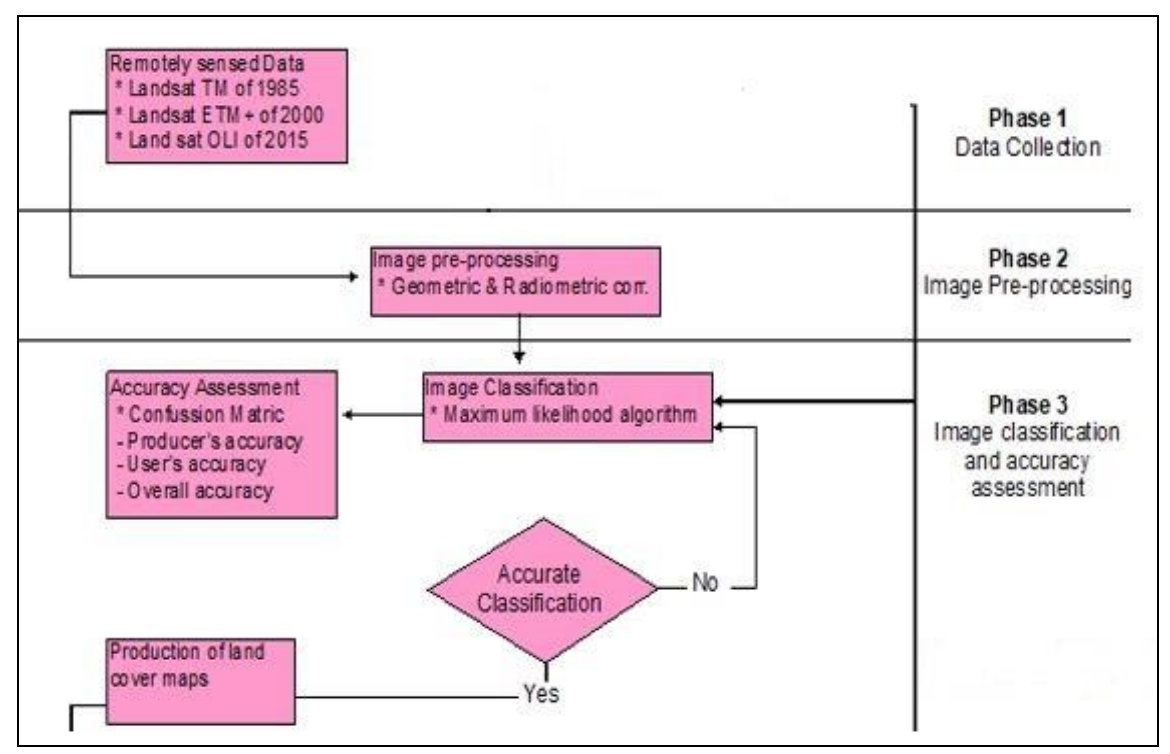

Figure 2. The methodology flowchart

\subsection{Image Pre-processing}

The raw data procured through satellite-sensor platforms mostly contain noises and distortion as well as other atmospheric errors. To rectify these, the data has to be pre-processed to confirm originality of the data. This differs on account of satellite images, which relies upon the image format, its initial condition and the kind of information required for it, as well the composition of the image scene. In the present study, image preprocessing was adopted to eliminate the noises and distortions obtainable in a raw data (imaging). This preliminary stage of image litigation will permit access to an uninterrupted image for further analysis. Then in addition, the phase will make image workable for it geometric and radiometric characteristics to resemble the radiant energy of the archetype scene. The scenes of Landsat imagery of the study were redressed through subjecting them to radiometric and geometric corrections. Then all Landsat scenes have been geometrically restituted with transformation of local map coordinates. This is to permit the radiometric and geometric characteristics of the image to match the radiant energy of the original scenes (Jensen and Cowen, 1999; Musa et al., 2018).
The collected images were radiometrically improved by utilizing the rescaling parameters accompanied in the metadata associated with the images. The image ratification was performed in two phase system: (a) the highest point of atmospheric reflectance were changed over to surfaces reflectance utilizing dark object subtraction (DOS), (b) the image digital/computerized numbers (DNs) were changed to the best of atmospheric reflectance. The analysis usually eliminate any atmospheric scattering obtained from original image of which pixel value representing background signature were fully erase from individual bands. Therefore, image-to-map rectification process by means of ground control point (GCPs) appearing in either maps or images, was employed to correct scenes of 2015 and it was used as the reference image to rectify the remaining scenes (Sang, 2013). The analysis was observing in two phases involving; $2^{\text {nd }}$ grade polynomial was utilized to transform image toward map geometry and raw/crude Landsat image pixel intensity rate were transposed to transformed geometry by utilizing the nearest neighbour resampling pattern. To avoid loss of fact and misclassification, a broadly used Root Mean Squired Error (RMSE) of \pm 0.5 pixel was guaranteed (Imani et al., 2014; Yuan et al., 2005) for accurate investigation. 


\section{RESULTS AND DISCUSSIONS}

This research was conducted to analyze change pattern particularly water level and assess its impact on the study area and examine the usability of satellite imagery, in such a way of assessing water level change in the lake over the last three decades of the basin. A comprehensive analysis has been done, supervised classifications by maximum likelihood algorithm were performed in this study. Nevertheless, the result of the accuracy assessment indicates that the image classifications have met the criteria for acceptance considering US Geological Survey (USGS) standard of image classification is $85 \%$ for overall accuracy (Anderson et al., 1976). Figures 3, 4 and 5 presented the derived change maps for the year 1985, 2000 and 2015 respectively.

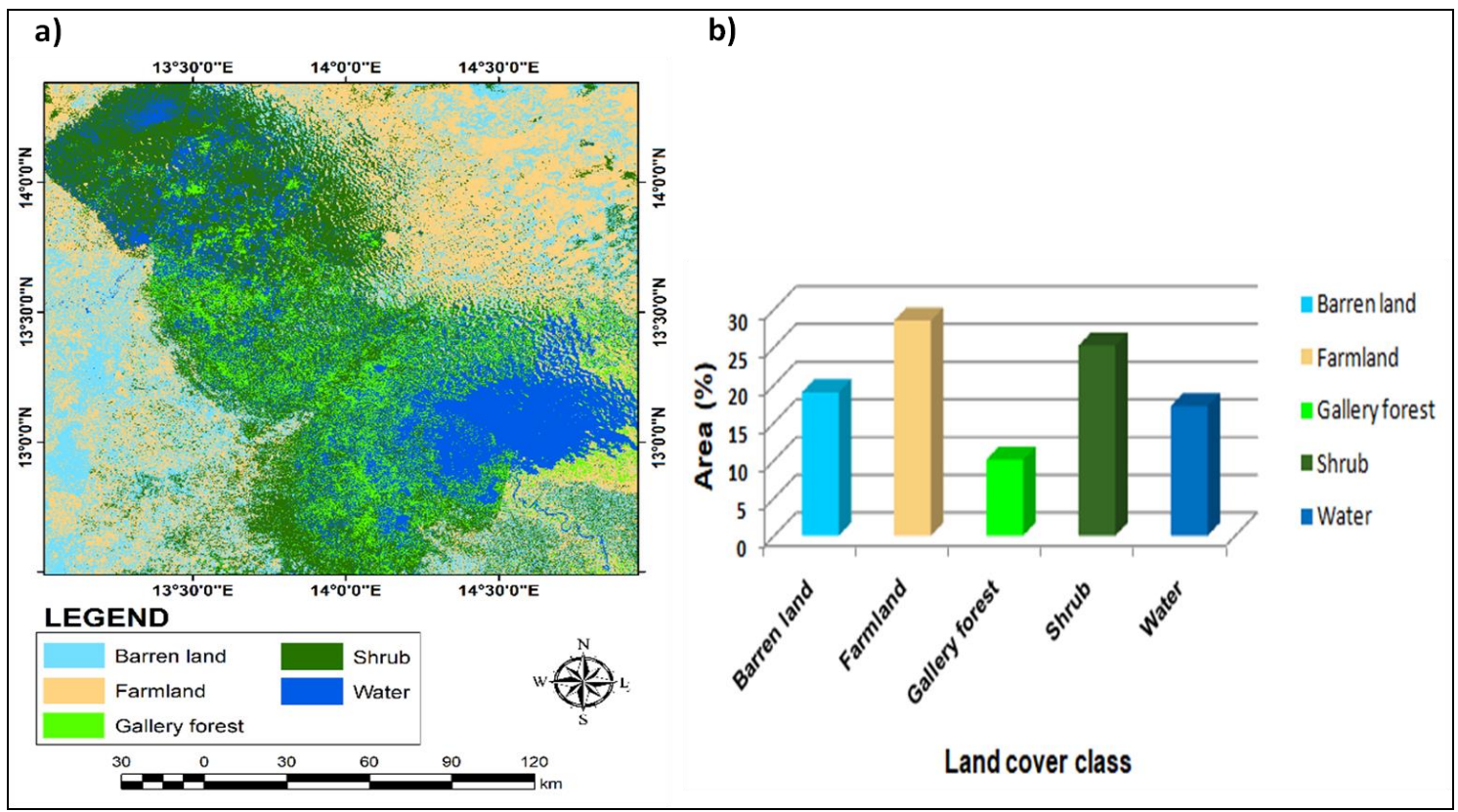

Figure 3. (a) Lake Chad change map in 1985, (b) area coverage percentage for each class

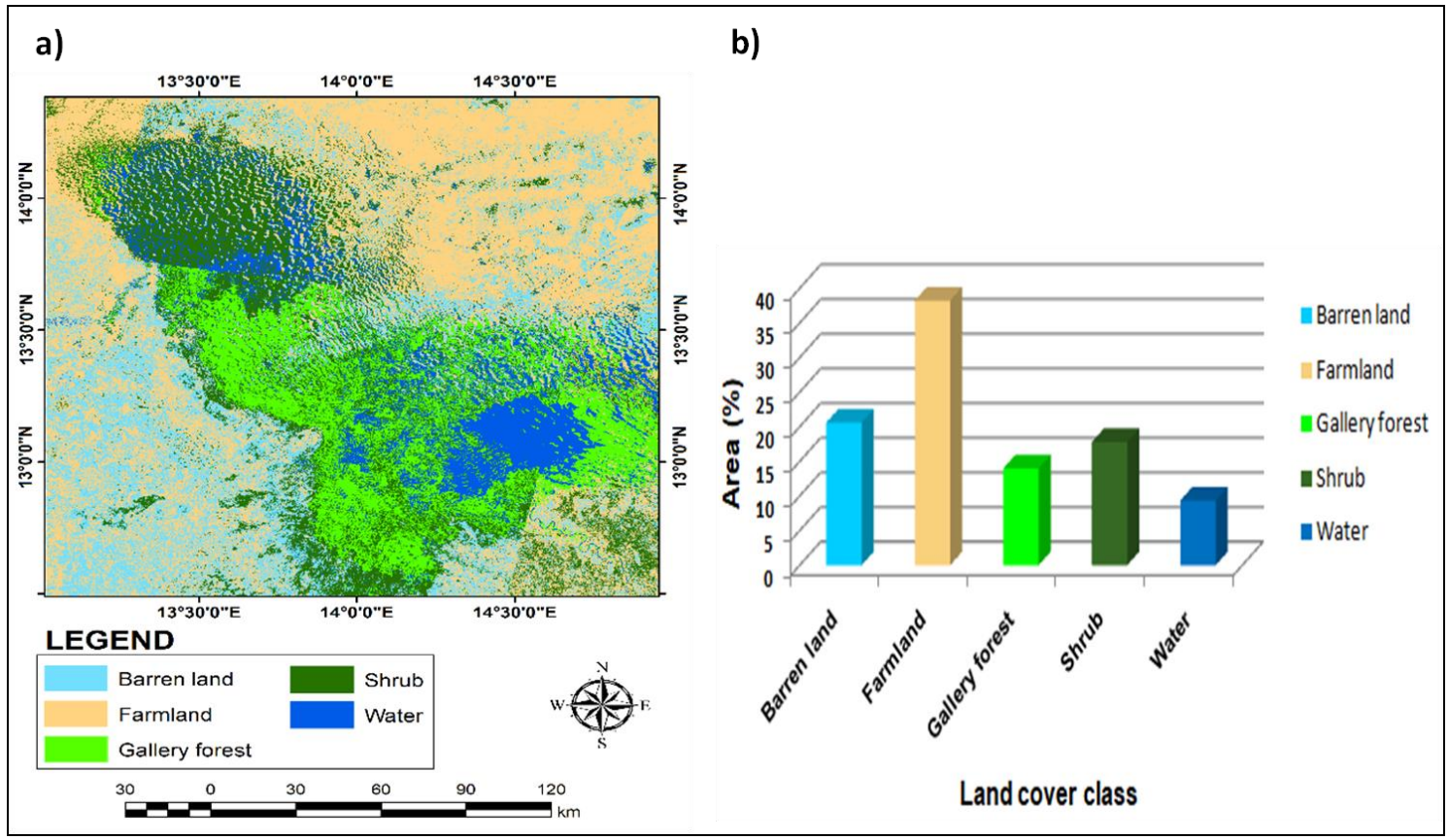

Figure 4. (a) Lake Chad change map in 2000, (b) area coverage percentage for each class 


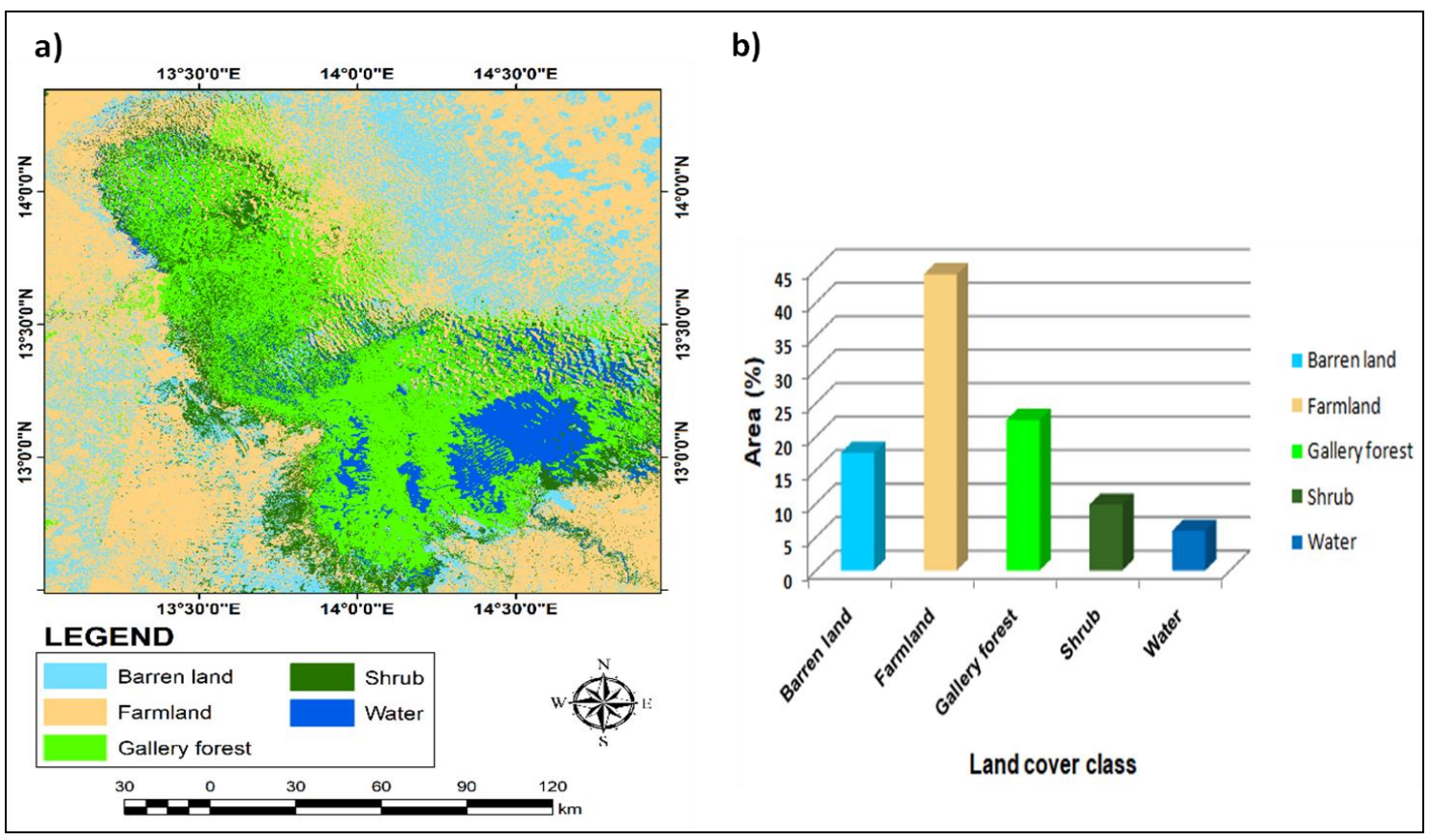

Figure 5. (a) Lake Chad change map in 2015, (b) area coverage percentage for each class

The whole classification assessments comprising the confusion matrices, producer's accuracies, user's, and overall accuracies with Kappa indexes of the classified images are summarized and presented in Table 2. The reasons for achieving the highest accuracy could be attributed to the coarse classification using five classes only. However, it can be observed that the derived maps have different classification accuracies, which could be attributed to the use of different multispectral bands and temporal variations in the images.

Table 2: Classification accuracies with overall kappa indexes.

\begin{tabular}{|c|c|c|c|c|c|c|}
\hline \multirow[b]{2}{*}{$\begin{array}{l}\text { Land Cover } \\
\text { Category }\end{array}$} & \multicolumn{2}{|c|}{1985} & \multicolumn{2}{|c|}{2000} & \multicolumn{2}{|c|}{2015} \\
\hline & $\begin{array}{c}\text { Producer's } \\
\text { Accuracy } \\
(\%)\end{array}$ & $\begin{array}{c}\text { User's } \\
\text { Accuracy } \\
(\%)\end{array}$ & $\begin{array}{c}\text { Producer's } \\
\text { Accuracy } \\
(\%)\end{array}$ & $\begin{array}{c}\text { User's } \\
\text { Accuracy } \\
(\%)\end{array}$ & $\begin{array}{c}\text { Producer's } \\
\text { Accuracy } \\
(\%)\end{array}$ & $\begin{array}{c}\text { User's } \\
\text { Accuracy } \\
(\%)\end{array}$ \\
\hline Gallery Forest & 100.00 & 90.00 & 93.46 & 90.91 & 89.19 & 90.00 \\
\hline Farmland & 86.44 & 97.14 & 82.86 & 82.86 & 73.53 & 71.43 \\
\hline Barren Land & 95.18 & 87.78 & 93.55 & 96.67 & 95.65 & 97.78 \\
\hline Water Body & 94.79 & 95.79 & 98.85 & 90.53 & 100.00 & 85.26 \\
\hline Shrub & 94.23 & 98.00 & 87.04 & 94.00 & 77.19 & 88.00 \\
\hline Overall Kappa & \multicolumn{2}{|c|}{92.24} & \multicolumn{2}{|c|}{88.49} & \multicolumn{2}{|c|}{82.72} \\
\hline Overall Accuracy & \multicolumn{2}{|c|}{93.80} & \multicolumn{2}{|c|}{90.80} & \multicolumn{2}{|c|}{86.20} \\
\hline
\end{tabular}

\section{CONCLUSION}

The present study analyzed the land changes patterns of Lake Chad for the past three decades using Landsat- TM for the 1985, Landsat-ETM+ for 2000, and Landsat - OLI for 2015. Supervised classification methods were used for the land cover analysis of the satellite images, then Landsat has capabilities for detecting numerous land change patterns. This study shows that Landsat is capable of detecting depletion of water bodies. Likewise, the land cover classes contained five categories such as; barren land, farmland, gallery forest, shrub and water body. Barren land has the total percentage of 17, 16 and 15 in 1985, 2000 and 2015. Farmland has 26, 41 and 43 in 1985, 2000 and 2015. Gallery forest has 9, 12 and 21 in 1985, 2000 and 2015. Shrub has 24, 21 and 9 in 1985, 2000 and 2015. Water body has 16, 9 and 4 in 1985, 2000 and 2015 respectively. The result indicated a remarkable declined of water body, shrub and barren land from 1985 to 2015 . On the other hand, a slight increments of gallery forest as well as high increments of farmland.

\section{ACKNOWLEDGEMENT}

The authors greatly acknowledge the federal government of Nigeria for providing financial support to the postgraduate studentship of the first author through Academic Staff Training and Development intervention fund for Nigerian Universities and Colleges. Research facilities used at Universiti Teknologi Malaysia, especially Geocoastal Research Unit are also acknowledged. 


\section{REFERENCES}

Babamaaji, R. A. and Lee, J. (2014). Land use/land cover classification of the vicinity of Lake Chad using NigeriaSat-1 and Landsat data. Environmental earth sciences. 71(10), 43094317.

Boronina, A. and Ramillien, G. (2008). Application of AVHRR imagery and GRACE measurements for calculation of actual evapotranspiration over the Quaternary aquifer (Lake Chad basin) and validation of groundwater models. Journal of Hydrology. 348(1-2), 98-109.

Candela, L., Elorza, F., Tamoh, K., Jiménez- Martínez, J. and Aureli, A. (2014). Groundwater modelling with limited data sets: the Chari-Logone area (Lake Chad Basin, Chad). Hydrological processes. 28(11), 3714-3727.

Cenci, L., Disperati, L., Persichillo, M. G., Oliveira, E. R., Alves, F. L. and Phillips, M. (2018). Integrating remote sensing and GIS techniques for monitoring and modeling shoreline evolution to support coastal risk management. GIScience \& remote sensing. 55(3), 355-375.

Chandio, I. A., Matori, A. N. B., WanYusof, K. B., Talpur, M. A. H., Balogun, A.-L. and Lawal, D. U. (2013). GIS-based analytic hierarchy process as a multicriteria decision analysis instrument: a review. Arabian Journal of Geosciences. 6(8), 3059-3066.

Gao, H., Bohn, T., Podest, E., McDonald, K. and Lettenmaier, D. (2011). On the causes of the shrinking of Lake Chad. Environmental Research Letters. 6(3), 034021.

mani, M., You, R.-J. and Kuo, C.-Y. (2014). Caspian Sea level prediction using satellite altimetry by artificial neural networks. International Journal of Environmental Science and Technology. 11(4), 1035-1042.

Jensen, J. R. and Cowen, D. C. (1999). Remote sensing of urban/suburban infrastructure and socio-economic attributes. Photogrammetric engineering and remote sensing. 65, 611622 .

Musa, S., Hashim, M. and Reba, M. (2018). Image Enhancement and Change Detection for Urban Sprawl Analysis of Bauchi Metropolis, Nigeria Using Remote Sensing and GIS Techniques. Advanced Science Letters. 24(5), 3802-3808.

Okonkwo, C. and Demoz, B. (2014). Identifying anthropogenic 'hotspots' and management of water resources in Lake Chad Basin using GIS. Journal of Natural Resources Policy Research. 6(2-3), 135-149.

Okpara, U. T., Stringer, L. C., Dougill, A. J. and Bila, M. D. (2015). Conflicts about water in Lake Chad: Are environmental, vulnerability and security issues linked? Progress in Development Studies. 15(4), 308-325.

Hjort, A., Fisheries, F., Aquaculture Department, R. P. and Division, E. (2012). Identification and reduction of climate change vulnerability in the fisheries of the Lake Chad Basin. FAO, Rome (Italy).
Qiang, Y. and Lam, N. S. (2015). Modeling land use and land cover changes in a vulnerable coastal region using artificial neural networks and cellular automata. Environmental monitoring and assessment. 187(3), 57.

Rokni, K., Ahmad, A., Selamat, A. and Hazini, S. (2014). Water feature extraction and change detection using multitemporal Landsat imagery. Remote sensing. 6(5), 4173-4189.

Sang, Y.-F. (2013). Improved wavelet modeling framework for hydrologic time series forecasting. Water resources management. 27(8), 2807-2821.

Yuan, F., Sawaya, K. E., Loeffelholz, B. C. and Bauer, M. E. (2005). Land cover classification and change analysis of the Twin Cities (Minnesota) Metropolitan Area by multitemporal Landsat remote sensing. Remote sensing of Environment. 98(23), 317-328.

Revised August 2019 